\title{
Metaplastic Effects of Ketamine and MK-801 on Glutamate Receptors Expression in Rat Medial Prefrontal Cortex and Hippocampus
}

\author{
Alessandro Piva ${ }^{1}$ - Lucia Caffino ${ }^{2}$ - Francesca Mottarlini ${ }^{2}$ - Nicholas Pintori ${ }^{1} \cdot$ Fernando Castillo Díaz $^{2}$. \\ Fabio Fumagalli $^{2} \cdot$ Cristiano Chiamulera $^{1}$
}

Received: 23 December 2020 / Accepted: 5 March 2021 / Published online: 15 March 2021

(C) The Author(s) 2021

\begin{abstract}
Ketamine and MK-801 by blocking NMDA receptors may induce reinforcing effects as well as schizophrenia-like symptoms. Recent results showed that ketamine can also effectively reverse depressive signs in patients' refractory to standard therapies. This evidence clearly points to the need of characterization of effects of these NMDARs antagonists on relevant brain areas for mood disorders. The aim of the present study was to investigate the molecular changes occurring at glutamatergic synapses $24 \mathrm{~h}$ after ketamine or MK-801 treatment in the rat medial prefrontal cortex (mPFC) and hippocampus (Hipp). In particular, we analyzed the levels of the glutamate transporter-1 (GLT-1), NMDA receptors, AMPA receptors subunits, and related scaffolding proteins. In the homogenate, we found a general decrease of protein levels, whereas their changes in the post-synaptic density were more complex. In fact, ketamine in the mPFC decreased the level of GLT-1 and increased the level of GluN2B, GluA1, GluA2, and scaffolding proteins, likely indicating a pattern of enhanced excitability. On the other hand, MK-801 only induced sparse changes with apparently no correlation to functional modification. Differently from mPFC, in Hipp, both substances reduced or caused no changes of glutamate receptors and scaffolding proteins expression. Ketamine decreased NMDA receptors while increased AMPA receptors subunit ratios, an effect indicative of permissive metaplastic modulation; conversely, MK-801 only decreased the latter, possibly representing a blockade of further synaptic plasticity. Taken together, these findings indicate a fine tuning of glutamatergic synapses by ketamine compared to MK- 801 both in the mPFC and Hipp.
\end{abstract}

Keywords Metaplasticity $\cdot$ Ketamine $\cdot$ MK- $801 \cdot$ Medial prefrontal cortex $\cdot$ Hippocampus

\section{Introduction}

Several studies have shown that drugs of abuse may induce permissive changes that subsequently affect synaptic plasticity events [1], through a mechanism that has been defined as "plasticity of synaptic plasticity," also called metaplasticity [2]. Metaplasticity has been observed at different cellular and behavioral levels and can be induced by modification of

Alessandro Piva and Lucia Caffino share the authorship.

Fabio Fumagalli and Cristiano Chiamulera share the seniorship.

Alessandro Piva

alessandro.piva@univr.it

1 Neuropsychopharmacology Lab, Section Pharmacology, Department Diagnostic \& Public Health, University of Verona, Policlinico GB Rossi, P.le Scuro 10, 37134 Verona, Italy

2 Department of Pharmacological and Biomolecular Sciences, University of Milano, Via Balzaretti 9, 20133 Milano, Italy synaptic plasticity or neural assembly and connectivity [3] or by the exposure to environmental enrichment, stress, or drugs of abuse [4-6].

In addition, metaplasticity has been characterized as a process that contributes to render neural circuits more crystallized and less susceptible to remodeling [7]. Nowadays, however, little is still known about metaplasticity as a phenomenon contrasting relapse, e.g., facilitating extinction or acting against the effect of determinant factors promoting drugseeking relapse. Finnie and Nader [8] proposed that the molecular events able to affect memory reactivation and reconsolidation act as metaplastic mechanisms. $N$-methyl-Daspartate (NMDA) receptor antagonists such as MK-801 and ketamine have been shown to induce metaplastic changes of long-term potentiation (LTP) by facilitating tetanus-induced LTP in ex vivo hippocampal slices $24 \mathrm{~h}$ after treatment [9-11]. Single ketamine dosing has been shown to induce a cascade of molecular events leading to enhanced synaptic activity in brain areas involved in mood, motivation, and emotional memory (e.g., $[12,13])$. On the other hand, repeated ketamine 
self-administration altered glutamate receptors expression and $\alpha$ CaMKII autophosphorylation when observed $24 \mathrm{~h}$ after the last infusion in the medial prefrontal cortex (mPFC), ventral striatum, and hippocampus (Hipp) $[14,15]$. These ketamine effects are commonly defined in literature as metaplastic effects $[10,16,17]$.

Recently, we showed that MK-801-induced metaplasticity was able to inhibit the reconsolidation of appetitive memory for the natural reward sucrose, together with a correlated increase of GluN2B, GluA1, and mGluR5 in NAc and GluN2B in the amygdala [18]. Moreover, we showed that acute ketamine given prior to context-induced relapse significantly inhibited responding, but no effects were observed on the reconsolidation of the contextual appetitive memory. The inhibition of renewal was correlated to decreased levels of GluA1 and mGluR5 in the Hipp, whereas the lack of effect on contextual memory reconsolidation was explained as resistance to destabilization due to decreased GluN2B expression [19].

In the present study, we aimed to further investigate MK801 and ketamine effects on the expression of glutamate transporter-1 (GLT-1), glutamate receptors (GluRs), and related scaffolding proteins in the mPFC and Hipp when given under an acute dosing regimen known to induce metaplastic changes $[9,10]$. Rats were treated with MK-801 or ketamine $24 \mathrm{~h}$ before the assessment of the expression of the GLT-1, NMDA receptor subunits GluN1, GluN2A, and GluN2B, the $\alpha$-amino-3-hydroxy-5-methyl-4-isoxazolepropionic acid (AMPA) receptor subunits GluA1 and GluA2, and their related scaffolding proteins both in the whole homogenate and in the post-synaptic density.

\section{Material and Methods}

\section{Animals}

Subjects were 20 male Sprague-Dawley rats (Charles River, Italy) weighing $300 \pm 30 \mathrm{~g}$ at the time of treatment. Rats were housed in pairs in temperature and humidity-controlled environment $\left(19-23{ }^{\circ} \mathrm{C}, 60 \pm 20 \%\right)$ on a 12-h light/dark cycle, with light $\mathrm{ON}$ at 7:30 p.m. Water and food were available ad libitum. Animals were treated during the dark phase of the light/dark cycle, and all the experimental procedures were carried out in accordance with the U.K. Animals (Scientific Procedures) Act of 1986 and associated guidelines and with EU Directive 2010/63/EU for animal experiments. All efforts were made to minimize animal suffering and to keep the lowest number of animals used.

\section{Pharmacological Treatment}

At day 1, 4 groups of rats (5 rats/group) were injected with ketamine $10 \mathrm{mg} / \mathrm{kg} / \mathrm{mL}$ i.v., saline solution $1 \mathrm{~mL} /$ $\mathrm{kg}$ i.v., MK-801 $4 \mathrm{mg} / \mathrm{kg} / \mathrm{mL}$ i.p., or saline solution 1 $\mathrm{mL} / \mathrm{kg}$ i.p. The doses of MK-801 and ketamine used here were selected based on previous metaplastic evidence. In fact, $4 \mathrm{mg} / \mathrm{kg}$ i.p. MK-801 was able to facilitate the induction of LTP in ex vivo CA1-subiculum synapses $24 \mathrm{~h}$ after the treatment, while $10 \mathrm{mg} / \mathrm{kg}$ i.v. ketamine was able to enhance the magnitude of LTP in ex vivo Schaffer collateral-CA1 synapses, both in an electrophysiological setting [9, 10]. These doses were also reported to affect reward-related behavior in our studies [18, 19]. At day 2, $24 \mathrm{~h}$ after injection, rats were anesthetized with intraperitoneally $350 \mathrm{mg} / \mathrm{kg} / 2 \mathrm{~mL}$ chloral hydrate (Fluka, Italy) and sacrificed. Brains were rapidly removed and medial prefrontal cortices (bregma $+3.20 \mathrm{~mm}$; [20] and hippocampi $(-3.30 \mathrm{~mm})$ were dissected from 2-mm-thick slices using a Coronal Brain Matrix (SouthPointe Surgical Supply, FL, USA). Tissues were immediately frozen on dry ice and stored at $-80{ }^{\circ} \mathrm{C}$.

\section{Western Blot Assays}

Proteins in the whole homogenate and post-synaptic density were analyzed as previously described with minor modifications [19]. Briefly, Hipp and mPFC were homogenized in a teflon-glass potter in cold $0.32 \mathrm{M}$ sucrose buffer pH 7.4 containing $1 \mathrm{mM}$ HEPES, $1 \mathrm{mM} \mathrm{MgCl}_{2}$, $1 \mathrm{mM} \mathrm{NaHCO}_{3}$, and $0.1 \mathrm{mM}$ PMSF, in presence of commercial cocktails of protease (Roche, Monza, Italy) and phosphatase (Sigma-Aldrich, Milan, Italy). An aliquot of each homogenate was then sonicated and stored at -20 ${ }^{\circ} \mathrm{C}$. The remaining homogenate was centrifuged at $800 \times g$ for $5 \mathrm{~min}$; the obtained supernatant was then centrifuged at $13,000 \times \mathrm{g}$ for $15 \mathrm{~min}$, obtaining a pellet. This pellet was resuspended in a buffer containing $75 \mathrm{mM} \mathrm{KCl}$ and $1 \%$ Triton X-100 and centrifuged at $100,000 \times g$ for $1 \mathrm{~h}$. The resulting supernatant, referred as Triton X-100 soluble fraction (TSF, extra-synaptic fraction), was stored at $20{ }^{\circ} \mathrm{C}$; the pellet, referred as PSD or Triton X-100 insoluble fraction (TIF, post-synaptic density), was homogenized in a glass-glass potter in $20 \mathrm{mM}$ HEPES, protease, and phosphatase inhibitors and stored at $-20{ }^{\circ} \mathrm{C}$ in presence of glycerol $30 \%$. Total proteins have been measured in the homogenate and TIF fractions according to the Bradford Protein Assay procedure (Bio-Rad, Milan, Italy), using bovine serum albumin as calibration standard.

Equal amounts of proteins of the homogenate $(10 \mu \mathrm{g})$ and of TIF fraction $(8 \mu \mathrm{g})$ were run on a sodium dodecyl sulfate- $8 \%$ polyacrylamide gel under reducing conditions and then electrophoretically transferred onto nitrocellulose membranes (GE Healthcare, Milan, Italy). Blots were blocked $1 \mathrm{~h}$ at room temperature with I-Block solution (Life Technologies Italia, Italy) in TBS $0.1 \%$ Tween-20 
buffer and incubated with antibodies against the proteins of interest.

The conditions of the primary antibodies were the following: anti GLT-1 (1:5000, AbCam), anti GluN1 (1:1000, Invitrogen), anti GluN2B (1:1000, Cell Signaling Technology Inc.), anti GluN2A (1:1000, Cell Signaling Technology Inc.), anti SAP102 (1:1000, AbCam), anti GluA1 (1:1000, Cell Signaling Technology Inc.), anti GluA2 (1:2000, Cell Signaling Technology Inc.), anti SAP97 (1:1000, AbCam), anti PSD95 (1:2000, Cell Signaling Technology Inc.), and anti $\beta$-Actin (1:10000, Sigma-Aldrich). Results were standardized using $\beta$-actin as the control protein, which was detected by evaluating the band density at $43 \mathrm{kDa}$. Immunocomplexes were visualized by chemiluminescence using the Chemidoc MP Imaging System (Bio-Rad Laboratories). Gels were run 3 times each and the results represent the average from 3 different western blots, averaged and normalized by using a specific correction factor [21]. Uncropped immunoblots related to the protein expression levels measured in the whole homogenate and post-synaptic density of medial prefrontal cortex and hippocampus are presented in Online resource 1.

\section{Statistical Analysis}

Data were collected in individual animals (independent determinations) and are presented as means and standard errors (SEM). Molecular changes produced by pharmacological treatment were analyzed by unpaired Student's $t$-test. Prism 8.0 (GraphPad) was used to analyze all the data. Statistical significance was assumed at $p<0.05$.

\section{Results}

\section{Effects of Pharmacological Intervention on Medial Prefrontal Cortex Protein Levels}

Western blot analysis in the mPFC $24 \mathrm{~h}$ after ketamine injection showed a significant decrease of GLT-1 protein levels in the total homogenate vs control $\left(-13.40 \pm 4.7 \%, t_{(8)}=2.879, p<.05\right.$, Student's $t$-test); no significant changes were detected $24 \mathrm{~h}$ after MK-801 $\left(-1.00 \pm 5.82, t_{(8)}=0.172, \mathrm{NS}\right)$ (Fig. 1). As far as concern NMDARs levels, in the total homogenate, ketamine decreased GluN1 and GluN2A subunit levels (respectively $32.00 \pm 12.40, t_{(8)}=2.58, p<.05$ and $-23.20 \pm 5.25, t_{(8)}=$ $4.42, p<.01)$, with no changes for GluN2B $\left(-7.00 \pm 5.49, t_{(8)}=\right.$ $1.28, \mathrm{NS})$. On the other hand, analysis of the post-synaptic density revealed a significant increase of GluN2B $\left(36.60 \pm 15.83, t_{(8)}\right.$ $=2.313, p<.05)$, with no changes for GluN1 and GluN2A ($24.20 \pm 26.91, t_{(8)}=0.899$ and $\left.8.40 \pm 17.78, t_{(7)}=0.472 ; \mathrm{NS}\right)$. Conversely, in the total homogenate, MK-801 injection only decreased GluN1 level $\left(-28.80 \pm 10.78, t_{(8)}=2.672, p<.05\right)$, with no effects on GluN2B and GluN2A $\left(-6.20 \pm 9.49, t_{(8)}=\right.$ 0.653 and $-12.60 \pm 11.29, t_{(8)}=1.116$; NS). Similarly, no differences in the levels of GluN1 and GluN2B were observed in the post-synaptic density $\left(-5.8 \pm 21.65, t_{(8)}=0.268 ;-0.60 \pm\right.$ $13.26, t_{(8)}=0.045$; NS) except for the decrease of GluN2A ($\left.33.00 \pm 11.28, t_{(7)}=2.925, p<.05\right)$ (Fig. 2).

Regarding AMPARs subunit levels, while GluA1 and GluA2 levels decreased in the homogenate $(-24.00 \pm 7.27$, $t_{(8)}=3.304$ and $\left.-28.60 \pm 11.26, t_{(8)}=2.539 ; p<.05\right)$ and increased in the post-synaptic density vs control (36.45 \pm $14.45, t_{(7)}=2.522$ and $\left.49.60 \pm 19.82, t_{(8)}=2.503 ; p<.05\right)$
Fig. 1 Effect of ketamine and MK-801 on glutamate transporter-1 (GLT-1) protein level in the total homogenate of mPFC $24 \mathrm{~h}$ after pharmacological treatments. Quantification of GLT-1 protein levels 24 after ketamine (a) or MK-801 (b) in the total homogenate. Below the graphs, representative immunoblots are shown for GLT-1 (62 $\mathrm{kDa})$ and $\beta$-actin (43 kDa) proteins in the homogenate of $\mathrm{mPFC}$. Data are shown as the mean + SEM and are expressed as percentage of the vehicle. Ketamine = solid column; MK-801 = grey column; vehicle $=$ open columns . $N=5$ rats/group. $* p<0.05$ vs vehicle; unpaired two-tailed Student's $t$-test

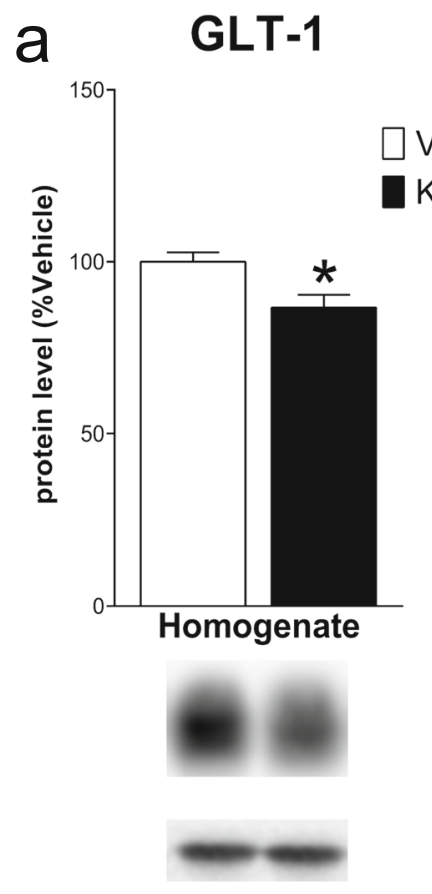

b GLT-1

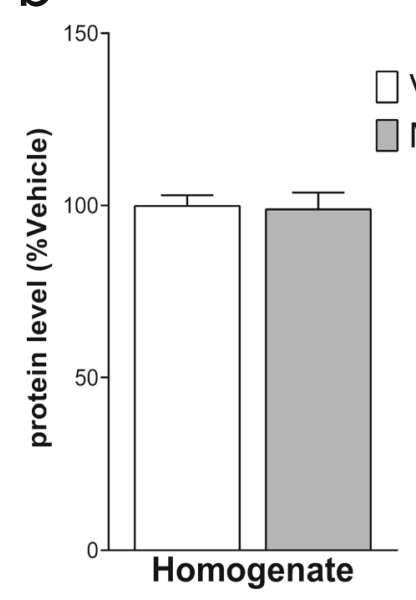

GLT-1

$\beta$-actin etamine
Vehicle

MK-801

(1)

,



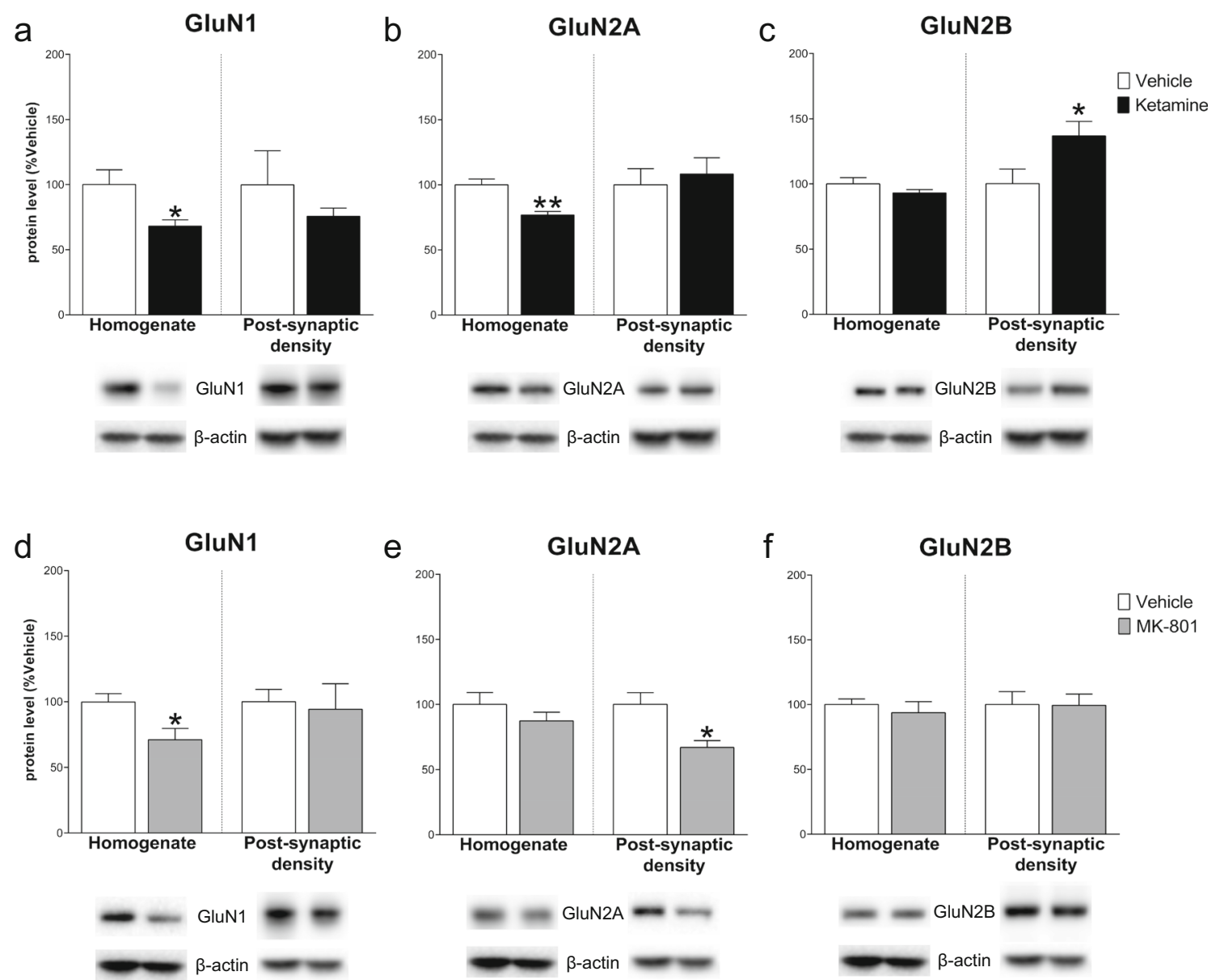

Fig. 2 Effect of ketamine and MK-801 on NMDARs subunits in the homogenate and post-synaptic density of $\mathrm{mPFC} 24 \mathrm{~h}$ after pharmacological treatments. Quantification of GluN1 (a, d), GluN2A $(\mathbf{b}, \mathbf{e})$, and GluN2B (c, f) subunit protein levels 24 after ketamine (top) or MK-801 (bottom) in the total homogenate or in the post-synaptic density of mPFC. Below the graphs, representative immunoblots are shown for

GluN1 (120 kDa), GluN2A (180 kDa), GluN2B (180 kDa), and $\beta$-actin $(43 \mathrm{kDa})$ in the homogenate and in the post-synaptic density of mPFC. Data are shown as the mean + SEM and are expressed as percentage of the vehicle. Ketamine = solid columns; MK- $801=$ grey columns; vehicle $=$ open columns. $N=5$ rats/group. $* p<0.05, * * p<0.01$ vs vehicle; unpaired two-tailed Student's $t$-test

after ketamine, MK-801 did not induce any significant modulation, neither in the homogenate (GluA1: $-8.80 \pm 10.33, t_{(8)}$ $=0.852 ;$ GluA2: $\left.-8.00 \pm 11.18, t_{(8)}=0.715 ; \mathrm{NS}\right)$ nor in the post-synaptic density (GluA1: $4.40 \pm 17.50, t_{(8)}=0.251$; GluA2: $-13.40 \pm 11.17, t_{(8)}=1.200$; NS) (Fig. 3).

Ketamine decreased the levels of scaffolding proteins PSD95, SAP102, and SAP97 in the homogenate (respectively, PSD95: $-24.60 \pm 7.25, t_{(8)}=3.393, p<.01$; SAP102: $18.00 \pm 7.29, t_{(8)}=2.468, p<.05 ;$ SAP97: $-41.40 \pm 12.62, t_{(8)}$ $=3.279, p<.05$ ), while increased both PSD95 and SAP102 in the post-synaptic density (PSD95: $35.00 \pm 13.14, t_{(8)}=2.663$; SAP102: $16.80 \pm 6.61, t_{(8)}=2.543 ; p<.05 ;$ SAP97: $5.40 \pm$ $\left.24.06, t_{(8)}=0.224, \mathrm{NS}\right)$. On the other hand, the effect of MK801 was less pronounced: in the homogenate, only SAP102 decreased compared to control (PSD95: $-5.80 \pm 4.89, t_{(8)}=$ 1.185, NS; SAP102: $-22.80 \pm 9.56, t_{(8)}=2.386, p<.05$; SAP97: $-2.00 \pm 12.95, t_{(8)}=0.154$, NS), while only SAP97 increased in the post-synaptic density (PSD95: $6.00 \pm 12.66$, $t_{(8)}=0.474, \mathrm{NS} ; \mathrm{SAP} 102: 0.60 \pm 8.57, t_{(8)}=0.070, \mathrm{NS}$; SAP97: $34.00 \pm 11.21, t_{(7)}=3.034, p<.05$ ) (Fig. 4 ).

As a functional correlate of synaptic plasticity and metaplasticity [8], we evaluated the ratio of GluN2A/ GluN2B and GluA1/GluA2 in the mPFC. Analysis in the homogenate revealed a significant decrease of GluN2A/GluN2B after ketamine vs control $(-17.80 \pm$ $\left.6.52, t_{(8)}=2.729, p<.05\right)$ but no changes in the postsynaptic density $\left(-11.80 \pm 11.39, t_{(7)}=1.036\right.$, NS $)$. Conversely, MK-801 decreased the GluN2A/GluN2B ratio in the post-synaptic density $\left(-23.80 \pm 7.86, t_{(8)}=\right.$ $3.029, p<.05)$ but not in the homogenate $(-5.40 \pm$ $7.44, t_{(8)}=0.726$, NS). Moreover, no changes resulted in the GluA1/GluA2 ratio, neither in the homogenate (ketamine: $6.60 \pm 14.24, t_{(8)}=0.464$; MK-801: $-2.00 \pm$ $8.75, t_{(8)}=0.229$; NS) nor in the post-synaptic density (ketamine: $2.80 \pm 12.93, t_{(7)}=0.217$; MK-801: $21.40 \pm$ 21.93, $t_{(8)}=0.976$; NS) (Fig. 5). 
Fig. 3 Effect of ketamine and MK-801 on AMPARs subunits in the homogenate and post-synaptic density of $\mathrm{mPFC} 24 \mathrm{~h}$ after pharmacological treatments.

Quantification of GluA1 (a, c) and GluA2 (b, d) subunit protein levels 24 after ketamine (top) or MK-801 (bottom) in the total homogenate or in the postsynaptic density of mPFC. Below the graphs, representative immunoblots are shown for GluA1 (108 $\mathrm{kDa})$, GluA2 (108 kDa), and $\beta$ actin $(43 \mathrm{kDa})$ in the homogenate and in the post-synaptic density of $\mathrm{mPFC}$. Data are shown as the mean + SEM and are expressed as percentage of the vehicle.

Ketamine $=$ solid columns; MK801 = grey columns; vehicle $=$ open columns. $N=5$ rats/group. $* p<0.05$ vs vehicle; unpaired two-tailed Student's $t$-test
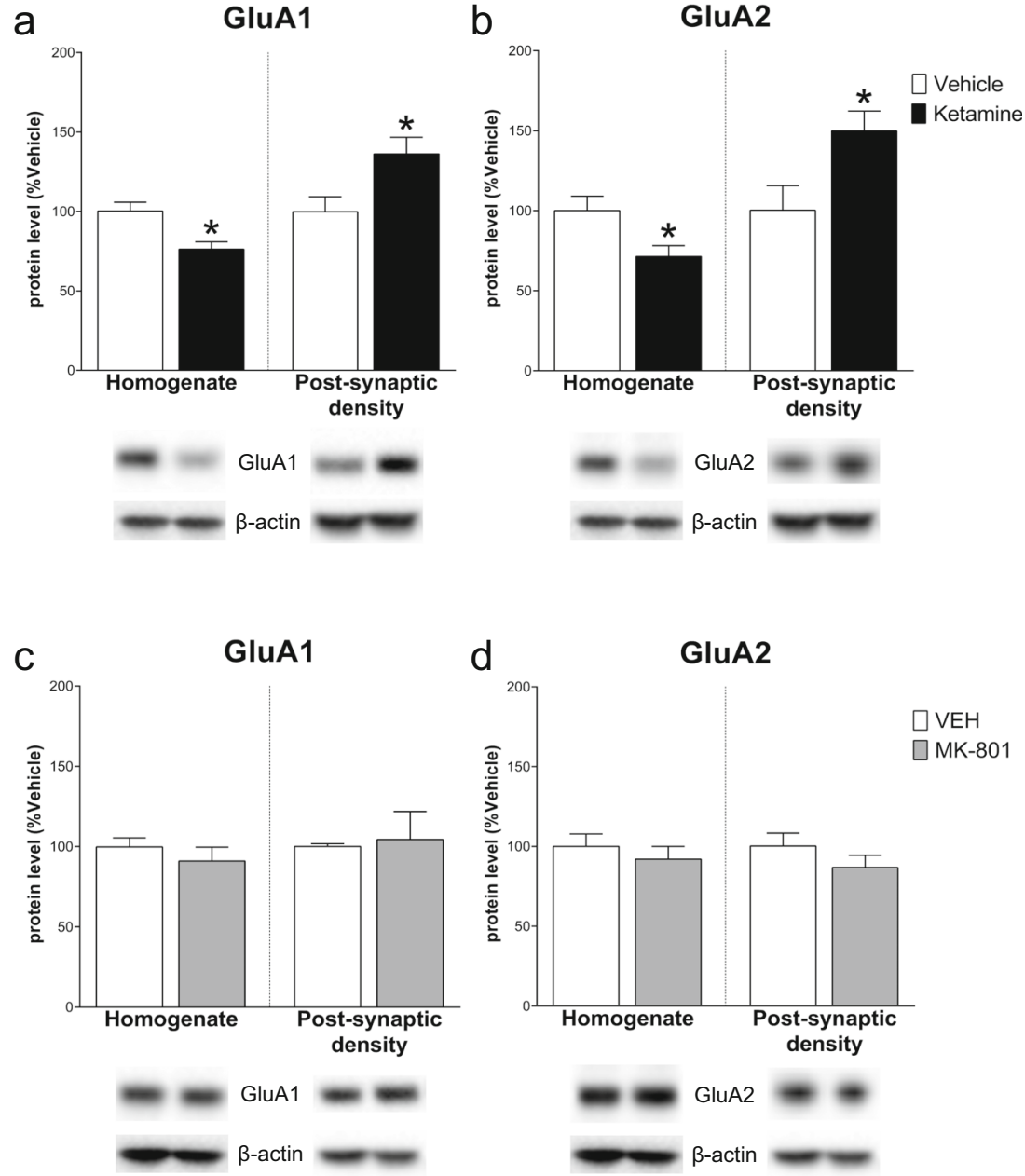

\section{Effects of Pharmacological Intervention on Hippocampal Protein Levels}

Analyses in the Hipp $24 \mathrm{~h}$ after pharmacological treatments revealed a significant decrease of GLT-1 levels after MK-801 $\left(-13.60 \pm 5.63, t_{(8)}=2.417, p<.05\right)$, but no changes after ketamine $\left(1.20 \pm 4.79, t_{(8)}=0.251\right.$, NS) (Fig. 6). All NMDARs subunit levels decreased both in total homogenate (GluN1: $-30.00 \pm 11.63, t_{(8)}=2.579$; GluN2A: $-26.60 \pm$ $8.26, t_{(8)}=3.222$; GluN2B: $-27.80 \pm 9.22, t_{(8)}=3.015 ; p<$ .05 ) and in the post-synaptic density (GluN1: $-23.60 \pm 8.17$, $t_{(8)}=2.891, p<.05 ;$ GluN2A: $-27.00 \pm 6.23, t_{(8)}=4.335, p<$ .01 ; GluN2B: $\left.-15.80 \pm 5.84, t_{(8)}=2.704, p<.05\right)$ after ketamine injection. MK-801 decreased NMDAR subunit levels in the homogenate (GluN1: $-50.60 \pm 15.24, t_{(8)}=$ 3.319; GluN2A: $-24.60 \pm 8.76, t_{(8)}=2.809$; GluN2B: $\left.22.60 \pm 7.53, t_{(8)}=3.001 ; p<.05\right)$ with no effects in the post-synaptic density (GluN1: $-0.40 \pm 8.90, t_{(8)}=0.045$; GluN2A: $-3.80 \pm 5.69, t_{(8)}=0.668 ;$ GluN2B: $-8.00 \pm$ $5.54, t_{(8)}=1.444$; NS) (Fig. 7).

Ketamine and MK-801 modulated in a similar way GluA1 protein levels, which decreased only in the post-synaptic density both after ketamine $\left(-21.40 \pm 5.11, t_{(8)}=4.192, p<\right.$ .01 ; homogenate: $-14.80 \pm 7.97, t_{(8)}=1.857$, NS) and MK$801\left(-21.80 \pm 7.72, t_{(8)}=2.823, p<.05\right.$; homogenate: $1.60 \pm$ $6.24, t_{(8)}=0.257$; NS). Conversely, GluA2 decreased both in the homogenate $\left(-40.80 \pm 9.94, t_{(8)}=4.10, p<.01\right)$ and in the post-synaptic density $\left(-50.60 \pm 10.48, t_{(8)}=4.829, p<.01\right)$ after ketamine, whereas MK-801 induced no effects in the homogenate $\left(-35.40 \pm 22.30, t_{(8)}=1.587\right.$; NS) and a significant increase in the post-synaptic density (GluA2: $55.60 \pm$ $13.20, t_{(8)}=4.213, p<.01$ ) (Fig. 8).

Finally, scaffolding protein levels were decreased in the post-synaptic density (PSD95: $-30.20 \pm 7.10, t_{(8)}=4.256, p$ $<.01$; SAP102: $-19.80 \pm 7.70, t_{(8)}=2.573, p<.05$; SAP97: $\left.36.40 \pm 8.34, t_{(8)}=4.364, p<.05\right)$ with no effects in the homogenate (PSD95: $-8.00 \pm 5.85, t_{(8)}=1.368$; SAP102: $1.40 \pm 6.00, t_{(8)}=0.234 ;$ SAP97: $-9.20 \pm 9.94, t_{(8)}=0.925$; NS) after ketamine. On the other hand, MK-801 decreased PSD95 and SAP97 both in the homogenate and postsynaptic density (PSD95: homogenate: $-29.60 \pm 9.95, t_{(8)}=$ 2.974, post-synaptic density: $-17.80 \pm 6.69, t_{(8)}=2.659 ; p<$ .05 ; SAP97: homogenate: $-30.40 \pm 9.69, t_{(8)}=3.138$, postsynaptic density: $\left.-29.80 \pm 11.36, t_{(8)}=2.623 ; p<.05\right)$. 

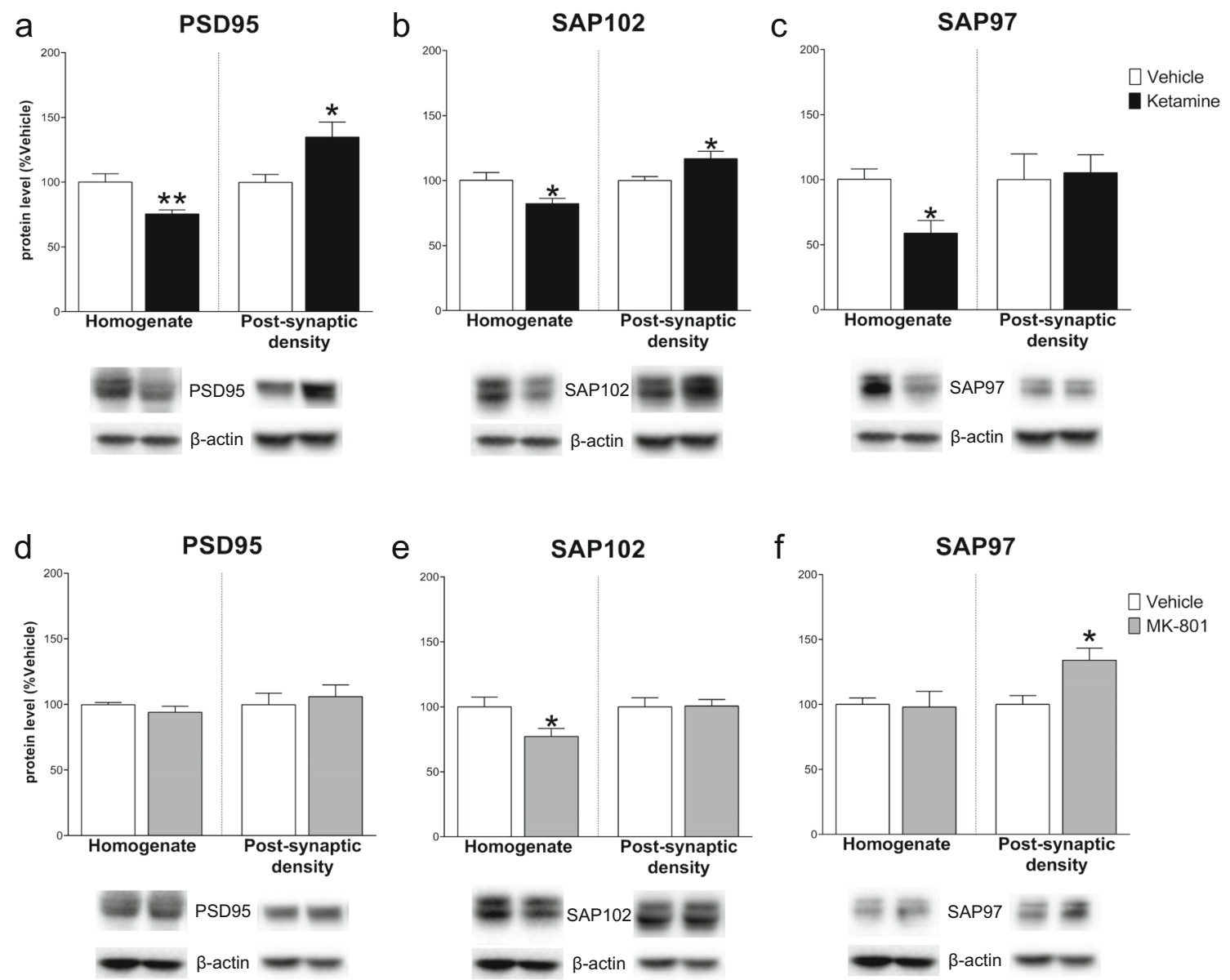

Fig. 4 Effect of ketamine and MK-801 on scaffolding protein levels in the homogenate and post-synaptic density of mPFC $24 \mathrm{~h}$ after pharmacological treatments. Quantification of PSD95 (a, d), SAP102 (b, e), and SAP97 (c, f) subunit protein levels 24 after ketamine (top) or MK-801 (bottom) in the total homogenate or in the post-synaptic density of mPFC. Below the graphs, representative immunoblots are shown for
PSD95 (95 kDa), SAP102 (102 kDa), SAP97 (97 kDa), and $\beta$-actin $(43 \mathrm{kDa})$ in the homogenate and in the post-synaptic density of mPFC. Data are shown as the mean + SEM and are expressed as percentage of the vehicle. Ketamine $=$ solid columns; MK- $801=$ dark grey columns; vehicle $=$ open columns. $N=5$ rats/group. $* p<0.05, * * p<0.01 \mathrm{vs}$ vehicle; unpaired two-tailed Student's $t$-test
SAP102 only decreased in the homogenate $(-22.00 \pm 6.86$, $t_{(8)}=3.206, p<.05$; post-synaptic density: $3.60 \pm 7.57, t_{(8)}=$ 0.475 , NS) (Fig. 9).

Evaluation of GluN2A/GluN2B and GluA1/GluA2 ratios revealed different treatment effects: ketamine increased GluA1/GluA2 ratio at both homogenate $(44.60 \pm$ $\left.15.28 ; t_{(8)}=2.920, p<.05\right)$ and post-synaptic density level $\left(60.60 \pm 16.24, t_{(8)}=3.733, p<.01\right)$, while decreased the GluN2A/GluN2B ratio only at the postsynaptic density level $\left(-13.60 \pm 4.84, t_{(8)}=2.813, p<\right.$ .05 ; homogenate: $-0.40 \pm 15.15, t_{(8)}=0.026$, NS). On the other hand, MK-801 only decreased GluA1/GluA2 ratio in the post-synaptic density $\left(-51.00 \pm 13.96, t_{(8)}=\right.$ $3.653, p<.01$; homogenate: $29.60 \pm 18.45, t_{(8)}=1.604$, NS) with no significant effects on GluN2A/GluN2B ratio vs control (homogenate: $-16.40 \pm 9.54, t_{(8)}=1.719$; post-synaptic density: $4.40 \pm 9.46, t_{(8)}=0.465$; NS) (Fig. 10).

\section{Discussion}

Our results show that ketamine and MK-801 differently modulate the homeostasis of the glutamate synapse in the mPFC and Hipp $24 \mathrm{~h}$ after acute treatment.

In the mPFC, ketamine induced remarkable changes compared to MK-801; in fact, except for GluN2B, in the total homogenate, all the molecular targets analyzed were decreased after ketamine compared to vehicle. Interestingly, ketamine injection induced an opposite effect in the postsynaptic density. MK-801 only decreased the obligatory NMDAR subunit GluN1 and the scaffolding protein SAP102 in the homogenate. In the post-synaptic density, MK-801 decreased GluN2A subunit and increased SAP97 scaffolding protein. The GluN2A/GluN2B ratio, previously indicated as metaplastic correlate [8], showed an increase in the homogenate after ketamine and in the post-synaptic density after MK- 801 . 
Fig. 5 Effect of ketamine and MK-801 on AMPARs and NMDARs subunit ratios in the homogenate and post-synaptic density of mPFC $24 \mathrm{~h}$ after pharmacological treatments. Ratios of GluA1/GluA2 (a, c) and GluN2A/Glu2B (b, d) protein levels 24 after ketamine (top) or MK-801 (bottom) in the total homogenate or in the postsynaptic density of mPFC. Data are shown as the mean + SEM and are expressed as percentage of the vehicle. Ketamine $=$ solid columns; MK-801 = dark grey columns; vehicle $=$ open columns $N=5$ rats/group. $* p<0.05$ vs vehicle; unpaired two-tailed Student's $t$-test
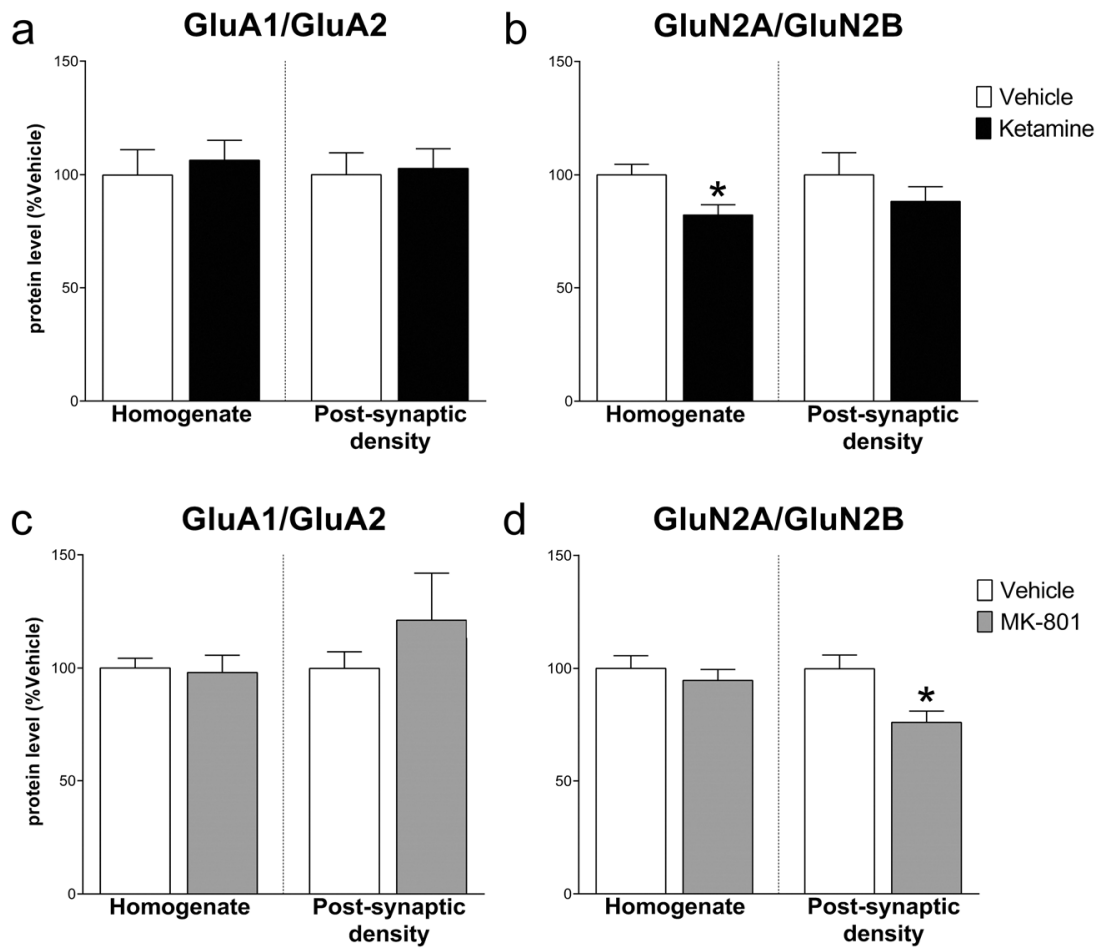

d

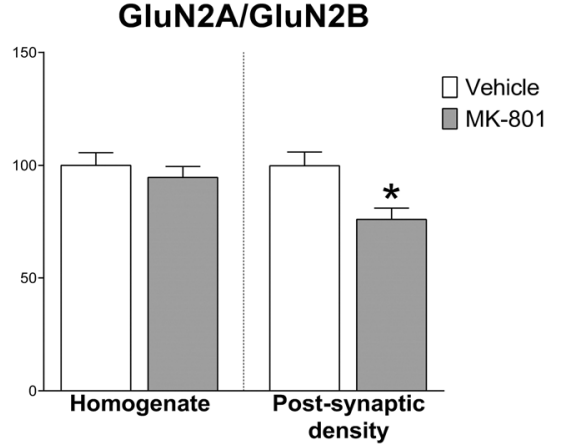

In the Hipp, ketamine decreased the level of all NMDARs subunits and of AMPAR subunit GluA2, whereas MK-801 significantly decreased glutamate transporter-1, all NMDARs subunits, and all scaffolding protein levels in the total homogenate. In the post-synapses, ketamine decreased the post-synaptic density levels of all NMDARs, AMPARs, and scaffolding proteins, while MK-801 increased GluA2 and decreased GluA1, PSD95, and SAP97 levels. GluA1/GluA2 and GluN2A/GluN2B ratios showed opposite changes after ketamine or MK-801: ketamine increased GluA1/GluA2 ratio both in the homogenate and in the post-synaptic density, while decreased GluN2A/GluN2B ratio in the post-synapses. On the other hand, MK- 801 only decreases the GluA1/GluA2 ratio in the post-synaptic density. A summary of ketamine and MK-
Fig. 6 Effect of ketamine and MK-801 on GLT-1 protein level in the total homogenate of Hipp $24 \mathrm{~h}$ after pharmacological treatments. Quantification of GLT-1 subunit protein levels 24 after ketamine (a) or MK-801 (b) in the total homogenate. Below the graphs, representative immunoblots are shown for GLT-1 (62 $\mathrm{kDa})$ and $\beta$-actin (43 kDa) proteins in the homogenate of Hipp. Data are shown as the mean + SEM and are expressed as percentage of the vehicle. Ketamine $=$ solid column; MK-801 = grey column; vehicle $=$ open columns . $N=5$ rats/group. $* p<0.05$ vs vehicle; unpaired two-tailed Student's $t$-test

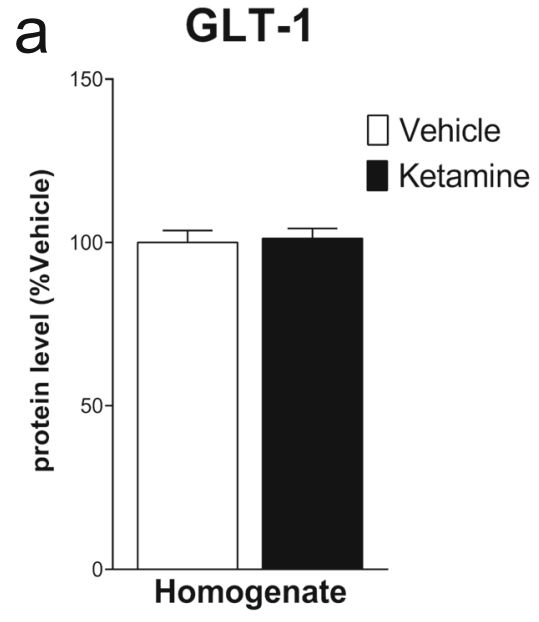

b GLT-1

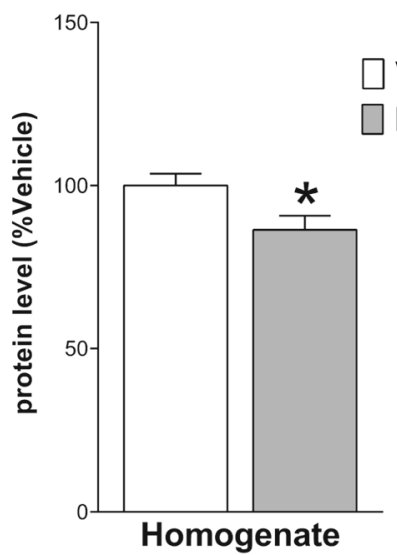

GLT-1

$\beta$-actin
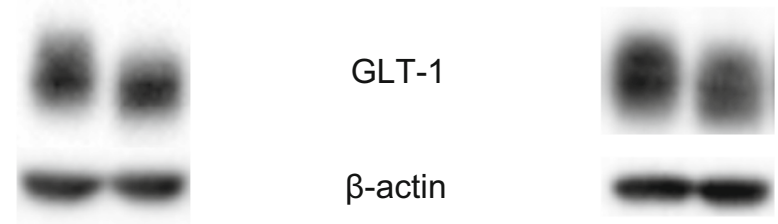

Vehicle

MK-801 

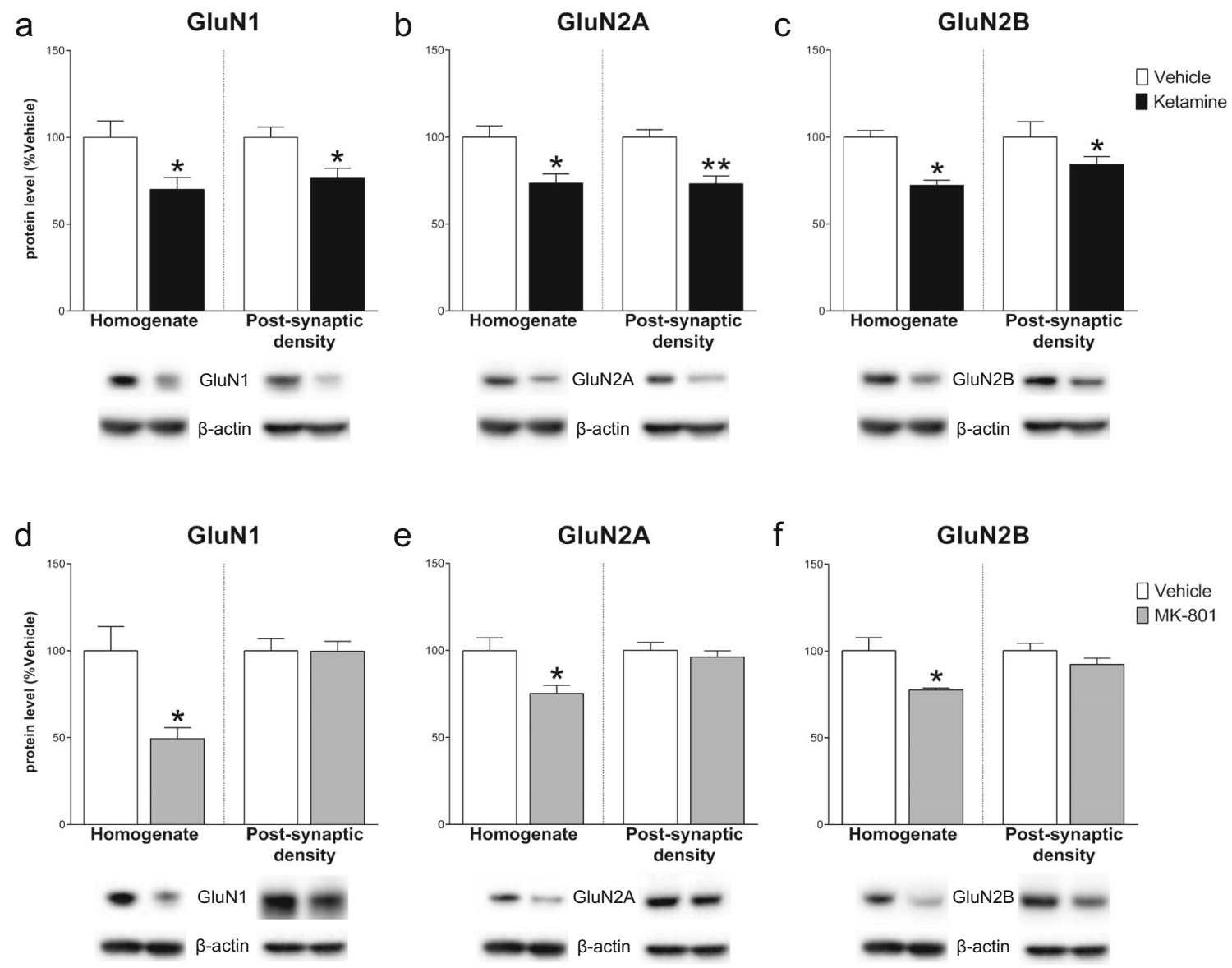

Fig. 7 Effect of ketamine and MK-801 on NMDARs subunits in the homogenate and post-synaptic density of Hipp $24 \mathrm{~h}$ after pharmacological treatments. Quantification of GluN1 (a, d), GluN2A (b, e), and GluN2B (c, f) subunit protein levels 24 after ketamine (top) or MK-801 (bottom) in the total homogenate or in the post-synaptic density of Hipp. Below the graphs, representative immunoblots are shown for GluN1 (120
kDa), GluN2A (180 kDa), GluN2B (180 kDa), and $\beta$-actin (43 kDa) in the homogenate and in the post-synaptic density of Hipp. Data are shown as the mean + SEM and are expressed as percentage of the vehicle. Ketamine $=$ solid columns; MK $-801=$ grey columns; vehicle $=$ open columns. $N=5$ rats/group. ${ }^{*} p<0.05, * * p<0.01$ vs vehicle; unpaired two-tailed Student's $t$-test
801 effects in the post-synaptic density of mPFC and Hipp is reported in Table 1.

The doses of MK-801 and ketamine herein used have been previously shown to induce metaplasticity in electrophysiological settings; in fact, systemic injection of $4 \mathrm{mg} / \mathrm{kg}$ MK801 facilitated LTP induction following subthreshold highfrequency stimulation in ex vivo CA1-subiculum synapses $24 \mathrm{~h}$ after the treatment [9]. Similarly, $10 \mathrm{mg} / \mathrm{kg}$ intravenous ketamine increased the magnitude of LTP induced by submaximal high-frequency stimulation in ex vivo hippocampal slices $24 \mathrm{~h}$ after injection and increased $\mathrm{Ca}^{2+}$-permeable subunits GluA1 and GluN2B at the cell surface in medial PFC and Hipp [10]. Ketamine facilitation of LTP $24 \mathrm{~h}$ post-dosing was also confirmed at subcutaneous $30 \mathrm{mg} / \mathrm{kg}$ and for intravenous $3 \mathrm{mg} / \mathrm{kg}$, with the latter facilitating LTP even at $72 \mathrm{~h}$ post-dosing [22]. More recently, we showed that this MK-801 dose administrated $24 \mathrm{~h}$ before sucrose instrumental memory reactivation was able to inhibit responding at reinstatement test, an effect correlated to glutamate receptors alterations in the nucleus accumbens and amygdala [18]. On the other hand, ketamine $24 \mathrm{~h}$ before contextual memory reactivation did not significantly affect the reconsolidation of sucrose contextual memory at reinstatement test, while significantly inhibited sucrose-seeking behaviors when administrated $24 \mathrm{~h}$ before relapse. Similarly, this ketamine dose induced glutamate receptors alterations in the nucleus accumbens and amygdala [19]. Thus, considering that these effects occurred long after the half-life of both the NMDARs antagonists in rats, i.e., approximately $1 \mathrm{~h}$ for ketamine and $2 \mathrm{~h}$ for MK-801 [23-25], our results further support the occurrence of metaplastic effects of both compounds on the glutamate synapse.

\section{The Effects of Ketamine and MK-801 in the Medial Prefrontal Cortex}

Recently, we demonstrated that ketamine markedly reduced the level of glutamate receptors and related scaffolding proteins in the crude synaptosomal fraction of mPFC, Hipp, and 
Fig. 8 Effect of ketamine and MK-801 on AMPARs subunits in the homogenate and post-synaptic density of Hipp $24 \mathrm{~h}$ after pharmacological treatments.

Quantification of GluA1 (a, c) and GluA2 (b, d) subunit protein levels 24 after ketamine (top) or MK-801 (bottom) in the total homogenate or in the postsynaptic density of Hipp. Below the graphs, representative immunoblots are shown for GluA1 (108 $\mathrm{kDa})$, GluA2 (108 kDa), and $\beta$ actin $(43 \mathrm{kDa})$ in the homogenate and in the post-synaptic density of Hipp. Data are shown as the mean + SEM and are expressed as percentage of the vehicle. Ketamine = solid columns; MK-801 = grey columns; vehicle $=$ open columns . $N=5$ rats/group. * $p<0.05$, ** $p<$ 0.01 vs vehicle; unpaired twotailed Student's $t$-test
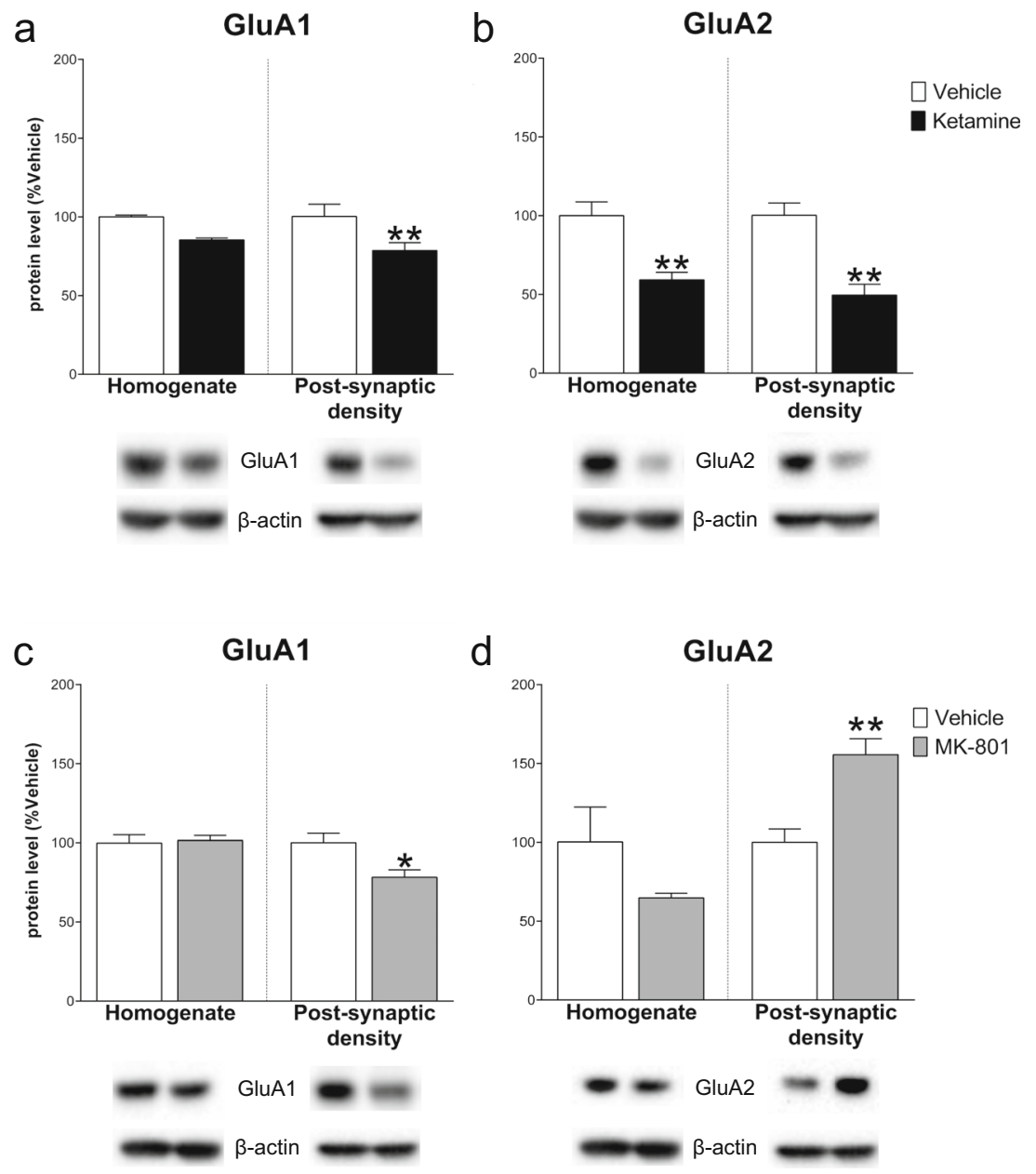

ventral striatum after long-term self-administration [14, 15]. The general decrease of glutamate receptors and scaffolding proteins in the $\mathrm{mPFC}$ homogenate that we observed in the present study after acute administration could be related, instead, to reduced gene expression or protein translation or to increased protein turnover, similarly to reports on PCP effects [26] and as seen in schizophrenic and depressed patients [27, 28]. This decrease could potentially be mediated by the glutamate excess in the synaptic cleft due to the decreased level of the glutamate transporter GLT-1. However, in contrast with this hypothesis, Burgdorf et al. [10] showed no differences in the levels of mRNA transcripts for GluN2B and GluA1 in $\mathrm{mPFC}$. The same authors reported also an increase of total cellular protein level for GluN2B and no differences for GluA1, partially in contrast with our results, i.e., no changes for GluN2B and a decrease for GluA1 in the homogenate.

The post-synaptic density profile of glutamate receptors and scaffolding proteins markedly differed from the homogenate: the increase of GluN2B subunit, as well as GluA1 and GluA2 subunits, indicates a general state of prefrontal cortex activation, in line with the disinhibition hypothesis of ketamine antidepressant action [29]. Moreover, the post-synaptic density levels of
GluN2B and GluA1 in $\mathrm{mPFC}$ are in line with the cell surface results reported by Burgdorf et al. [10].

Interestingly, the ketamine-induced effect on GluN2B was paralleled by an increase in its scaffolding proteins PSD95 and SAP102. The level of PSD95 was shown to be decreased in both depressed subjects and animal models of depression [28], and this decrease was shown to be attenuated by acute ketamine [30, 31]. Moreover, a decrease in SAP102-enconding transcripts was detected in the striatum of major depressed and schizophrenic patients [32]. Considering their role in the formation, trafficking, and stabilization of NMDARs and AMPARs at excitatory synapses $[33,34]$, we can hypothesize that ketamine-induced increase of scaffolding protein in PSD herein observed is probably involved in a cortical increased trafficking and stabilization of glutamate receptors that might underlie ketamine antidepressant effects.

To note, the decrease of the glutamate transporter GLT-1 after ketamine in $\mathrm{mPFC}$ could be referred to different factors. In fact, the decrease of GLT-1, and thus the increase of glutamate synaptic concentration, has been linked to the development and maintenance of abuse to different substances, such 

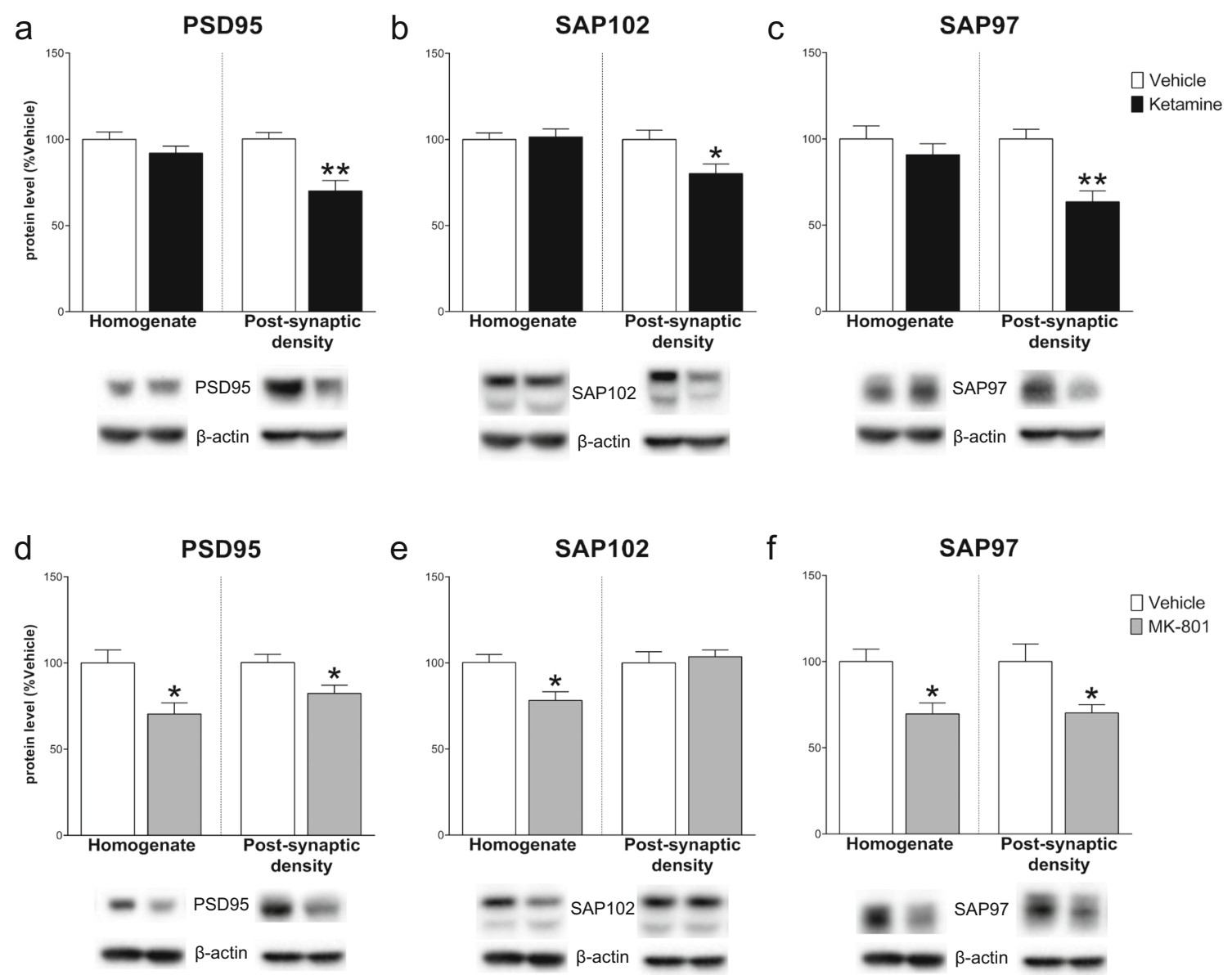

Fig. 9 Effect of ketamine and MK-801 on scaffolding protein levels in the homogenate and post-synaptic density of Hipp $24 \mathrm{~h}$ after pharmacological treatments. Quantification of PSD95 (a, d), SAP102 (b, e), and SAP97 (c, f) subunit protein levels 24 after ketamine (top) or MK-801 (bottom) in the total homogenate or in the post-synaptic density of Hipp. Below the graphs, representative immunoblots are shown for PSD95 (95

kDa), SAP102 (102 kDa), SAP97 (97 kDa), and $\beta$-actin (43 kDa) in the homogenate and in the post-synaptic density of Hipp. Data are shown as the mean + SEM and are expressed as percentage of the vehicle. Ketamine $=$ solid columns; MK- $801=$ dark grey columns; vehicle $=$ open columns. $N=5$ rats/group. ${ }^{*} p<0.05, * * p<0.01$ vs vehicle; unpaired two-tailed Student's $t$-test

as cocaine, nicotine, and ethanol, and the increase of GLT-1 in $\mathrm{mPFC}$ and nucleus accumbens was shown to correlate to relapse inhibition [35-37]. Thus, this increase could be a metaplastic effect of ketamine addictive properties lasting longer after acute administration. Nevertheless, this could as well be a sign of its antidepressant action, since recent reports demonstrated that glial GLT-1 blockade in mPFC contributes to the rapid onset of ketamine antidepressant effects $[38,39]$ and the astrocytic GLT-1 deficiency correlates to decreased anxiety and depression in a mouse model [40].

The glutamatergic modulation induced by MK-801 in the $\mathrm{mPFC}$ was different compared to ketamine, and few studies have specifically investigated the level of GluN1 and GluN2A subunits as well as scaffolding proteins after acute MK-801 in mPFC [41, 42]. To note, Xi and colleagues reported a significant downregulation of NMDARs subunits expressing-mRNA transcripts and protein levels in both pyramidal cells and parvalbumincontaining interneurons after acute high doses of MK-
801 [41], a mechanism that could underlie the schizophrenia-like symptoms usually observed after acute or chronic administration.

\section{The Effects of Ketamine and MK-801 in the Hippocampus}

In the Hipp, while MK-801-induced reduction of NMDARs was limited to the homogenate, ketamine decreased NMDARs also in the post-synaptic density, an effect that could be hypothesized to be related to a finer tuning of glutamatergic synapses by ketamine compared to MK- 801 . Previous research has reported a sustained decrease of GluN1 as well as a rapid but transient decrease of GluN2A and GluN2B as a molecular correlate of ketamine antidepressant action in Hipp [43] and of other antidepressant drugs action on stress-induced receptors upregulation [44]. On the contrary, Burgdorf and colleagues reported an increase of GluN2B (and GluA1) after $10 \mathrm{mg} / \mathrm{kg}$ i.v. ketamine in the cell 
Fig. 10 Effect of ketamine and MK-801 on AMPARs and NMDARs subunit ratios in the homogenate and post-synaptic density of Hipp $24 \mathrm{~h}$ after pharmacological treatments. Ratios of GluA1/GluA2 (a, c) and GluN2A/Glu2B (b, d) protein levels 24 after ketamine (top) or MK-801 (bottom) in the total homogenate or in the postsynaptic density of Hipp. Data are shown as the mean + SEM and are expressed as percentage of the vehicle. Ketamine $=$ solid columns; MK-801 = dark grey columns; vehicle $=$ open columns. $N$ $=5$ rats/group. $* p<0.05, * * p<$ 0.01 vs vehicle; unpaired twotailed Student's $t$-test a

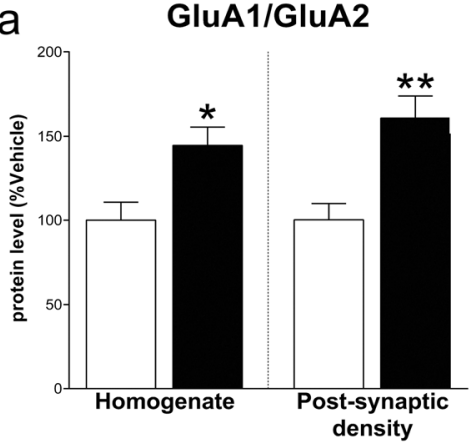

C

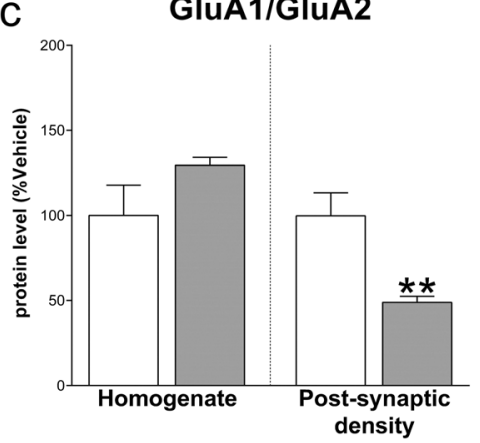

b

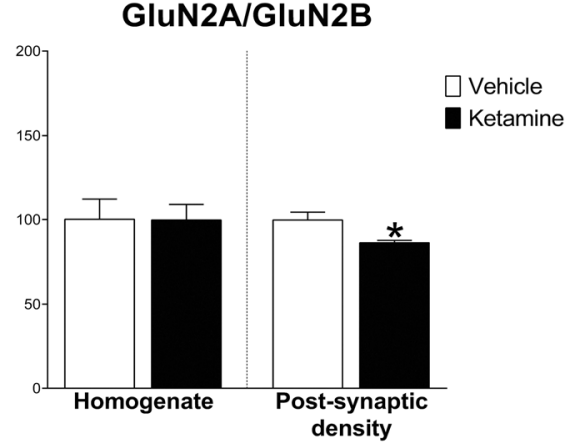

d

GluN2A/GIuN2B

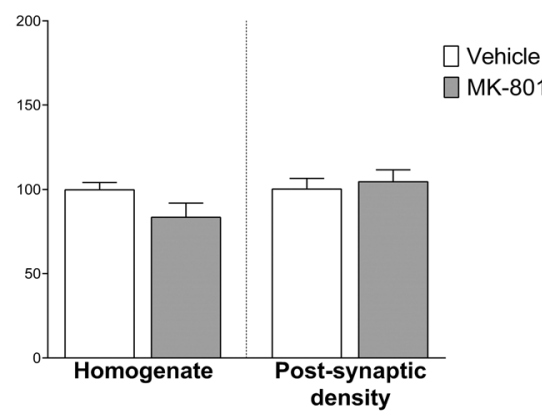

surface of Hipp [10]. These discrepancies could be related to the different routes of administration, doses $(30 \mathrm{mg} / \mathrm{kg}$ i.p. ketamine for Xia et al.), or cellular compartments analyzed, but further studies are needed to disambiguate these differences.

As far as concern AMPARs subunits, GluA1 was decreased at post-synaptic level by both compounds, with no changes in the homogenate. Moreover, while ketamine decreased GluA2 in the homogenate and in the post-synaptic density, MK-801 increased GluA2 in the post-synaptic density. Previous evidence indicates AMPARs activation and
GluA1 increase in Hipp as fundamental for ketamine antidepressant action, likely through an mTOR activationdependent mechanism [45-47]. In contrast, here, we observed the decrease of GluA1 after both NMDARs antagonists, similarly to the addiction-related effects exerted by ketamine long-term self-administration we previously reported [14].

Finally, the finer tuning of glutamate synapses by ketamine compared to MK-801 is further suggested by the results on scaffolding proteins. Ketamine reduced PSD95, SAP102, and SAP97 only in the post-synaptic density, while MK-801 decreased scaffolding proteins both in the homogenate and in the
Table 1 Summary table of ketamine and MK-801 effects on glutamate transmission components evaluated in the postsynaptic density of mPFC and Hipp $24 \mathrm{~h}$ after treatment

\begin{tabular}{|c|c|c|c|c|c|}
\hline \multicolumn{3}{|c|}{$\mathrm{mPFC}$} & \multicolumn{3}{|c|}{ Hipp } \\
\hline Ket & & MK-801 & Ket & & MK-801 \\
\hline$\downarrow$ & GLT-1 & $=$ & $=$ & GLT-1 & $\downarrow$ \\
\hline$=$ & GluN2A & $\downarrow$ & $\downarrow$ & GluN2A & $=$ \\
\hline$\uparrow$ & GluN2B & $=$ & $\downarrow$ & GluN2B & $=$ \\
\hline$=$ & GluN2A/GluN2B ratio & $\downarrow$ & $\downarrow$ & GluN2A/GluN2B ratio & $=$ \\
\hline$\uparrow$ & GluA1 & $=$ & $\downarrow$ & GluA1 & $\downarrow$ \\
\hline$\uparrow$ & GluA2 & $=$ & $\downarrow$ & GluA2 & $\uparrow$ \\
\hline$=$ & GluA1/GluA2 ratio & $=$ & $\uparrow$ & GluA1/GluA2 ratio & $\downarrow$ \\
\hline$\uparrow$ & PSD95 & $=$ & $\uparrow$ & PSD95 & $=$ \\
\hline$\uparrow$ & SAP102 & $=$ & $\downarrow$ & SAP102 & $=$ \\
\hline$=$ & SAP97 & $\uparrow$ & $\downarrow$ & SAP97 & $\downarrow$ \\
\hline
\end{tabular}

Symbols: $\uparrow=$ significant increase; $\downarrow=$ significant decrease; $0=$ no change vs vehicle 
post-synaptic density. These neuroplastic changes could reflect an enhanced membrane receptors instability as well as a reduction of spine density or spine head volume, suggesting an ambiguous morphological and functional synaptic alteration after acute NMDARs antagonism, a pattern of modification that is more likely referable to a profile of mood disorders [48, 49]. In particular, the decrease of PSD95 in the postsynaptic density of hippocampus after ketamine is indeed more difficult to interpret, with respect to the available literature. In fact, in disagreement with our results, ketamine is usually applied to reverse PSD95 reduction induced by stressful conditions $[30,31]$.

\section{Metaplastic Effects of NMDARs Antagonists in Medial Prefrontal Cortex and Hippocampus}

By a metaplasticity standpoint, it appears that ketamine induced a global change of all the components of glutamatergic transmission, while MK-801 changes were sparser and more limited to some subunits and scaffolding proteins in $\mathrm{mPFC}$. It is important to note that the ketamine-induced increase of GluN2B and AMPARs subunits observed in the $\mathrm{mPFC}$ closely resembles the receptor changes observed after acute and repetitive substance abuse and withdrawal in the ventral tegmental area and in the nucleus accumbens $[50,51]$. However, the glutamatergic changes reported here in $\mathrm{MPFC}$ are in contrast to the self-administered ketamine effects we previously observed [14, 15], suggesting a differential modulation of the glutamatergic tone by "antidepressant" vs "addictive" ketamine dose regimen. Moreover, considering the GluN2A/GluN2B ratio as an index of metaplasticity [8], we can conclude that both ketamine and MK-801 induced metaplastic effects, as both the compounds decrease the ratio thus determining a relative increase of the more $\mathrm{Ca}^{2+}$-permeable NMDAR subunit GluN2B in the mPFC, respectively in the total homogenate and in the postsynaptic density.

In Hipp, we observed a ketamine-induced modulation of AMPAR subunits resulting in a relative increase of GluA1/GluA2 functional ratio. This increase, in parallel with a relative decrease of GluN2A/GluN2B ratio, points to a general metaplastic enhancement of synaptic activity in the Hipp after ketamine, mediated by a relative heightening of calcium influx due to increased GluA1 and GluN2B relative levels. On the other hand, the opposite modulation of AMPARs subunits by MK-801, resulting in a decrease of GluA1/GluA2 ratio, most likely impairs hippocampal activity, presumably leading to a synaptic "crystallization" characterized by less susceptibility to structural and functional modification.

In conclusion, our study showed structural changes of glutamatergic synapses induced by the NMDARs antagonists MK-801 and ketamine that we could define as metaplastic. We hypothesize that the cascade of glutamatergic changes induced under this mode of dosing might affect synaptic efficiency and its modification by subsequent stimulations (e.g., tetanus, stressful conditions, and memory reactivation). Indeed, the same NMDARs antagonists can exert both protective and harmful effects on subjects suffering from mood disorders: the former, by ameliorating depressive symptoms in depressed patients, and the latter, by inducing or exacerbating psychotic symptoms. The state dependency of NMDARs antagonism final outcome is in line with the definition of ketamine antidepressant effects as metaplastic phenomena in clinical and preclinical evidence. In fact, depending on the basal state of glutamatergic synapses and on the therapeutic intervention applied closely to the treatment, ketamine and, to a lesser extent, MK-801 could act as reliable pharmacological strategies against mood disorders, such as depression or addiction. Considering the versatility action of NMDARs antagonism that could mediate addictive as well as therapeutic effects, further efforts are needed to clearly disambiguate the molecular and behavioral processes underpinning these metaplastic properties.

Supplementary Information The online version contains supplementary material available at https://doi.org/10.1007/s12035-021-02352-7.

Code Availability Not applicable.

Author Contribution Alessandro Piva and Nicholas Pintori performed the pharmacological treatments. Lucia Caffino, Francesca Mottarlini, and Fernando Castillo Díaz performed and analyzed the data of western blot assays. Fabio Fumagalli, Cristiano Chiamulera, Alessandro Piva, and Lucia Caffino planned and designed the whole study. The first draft of the manuscript was written by Alessandro Piva, Lucia Caffino, and Cristiano Chiamulera, and all authors commented on previous versions of the manuscript. All authors read and approved the final manuscript.

Funding Open access funding provided by Università degli Studi di Verona within the CRUI-CARE Agreement. This work was supported by grants from MIUR Progetto eccellenza.

Data Availability The authors confirm that the data supporting the findings of this study are available within the article and its supplementary materials. The raw data are available from Lucia Caffino (lucia.caffino@unimi.it) upon reasonable request.

\section{Declarations}

Ethics Approval All the experimental procedures were carried out in accordance with the U.K. Animals (Scientific Procedures) Act of 1986 and associated guidelines and with EU Directive 2010/63/EU for animal experiments. All efforts were made to minimize animal suffering and to keep the lowest number of animals used. 
Consent to Participate Not applicable.

\section{Consent for Publication Not applicable.}

Conflict of Interest The authors declare no competing interests.

Open Access This article is licensed under a Creative Commons Attribution 4.0 International License, which permits use, sharing, adaptation, distribution and reproduction in any medium or format, as long as you give appropriate credit to the original author(s) and the source, provide a link to the Creative Commons licence, and indicate if changes were made. The images or other third party material in this article are included in the article's Creative Commons licence, unless indicated otherwise in a credit line to the material. If material is not included in the article's Creative Commons licence and your intended use is not permitted by statutory regulation or exceeds the permitted use, you will need to obtain permission directly from the copyright holder. To view a copy of this licence, visit http://creativecommons.org/licenses/by/4.0/.

\section{References}

1. Creed MC, Lüscher C (2013) Drug-evoked synaptic plasticity: beyond metaplasticity. Curr Opin Neurobiol 23(4):553-558. https:// doi.org/10.1016/j.conb.2013.03.005

2. Abraham WC, Bear MF (1996) Metaplasticity: the plasticity of synaptic plasticity. Trends Neurosci 19(4):126-130. https://doi. org/10.1016/s0166-2236(96)80018-x

3. Abraham WC, Richter-Levin G (2018) From synaptic metaplasticity to behavioral metaplasticity. Neurobiol Learn Mem 154:1-4. https://doi.org/10.1016/j.nlm.2018.08.015

4. Eckert MJ, Abraham WC (2013) Effects of environmental enrichment exposure on synaptic transmission and plasticity in the hippocampus. Curr Top Behav Neurosci 15:165-187. https://doi.org/10. 1007/7854_2012_215

5. Schmidt MV, Abraham WC, Maroun M, Stork O, Richter-Levin G (2013) Stress-induced metaplasticity: from synapses to behavior. Neuroscience 250:112-120. https://doi.org/10.1016/j. neuroscience.2013.06.059

6. Neuhofer D, Kalivas P (2018) Metaplasticity at the addicted tetrapartite synapse: a common denominator of drug induced adaptations and potential treatment target for addiction. Neurobiol Learn Mem 154:97-111. https://doi.org/10.1016/j.nlm.2018.02.007

7. Chiamulera C, Piva A, Abraham WC (2021) Glutamate receptors and metaplasticity in addiction. Curr Opin Pharmacol 56:39-45. https://doi.org/10.1016/j.coph.2020.09.005

8. Finnie PS, Nader K (2012) The role of metaplasticity mechanisms in regulating memory destabilization and reconsolidation. Neurosci Biobehav Rev 36(7):1667-1707. https://doi.org/10.1016/j. neubiorev.2012.03.008

9. Buck N, Cali S, Behr J (2006) Enhancement of long-term potentiation at CA1-subiculum synapses in MK-801-treated rats. Neurosci Lett 392(1-2):5-9. https://doi.org/10.1016/j.neulet.2005.08.054

10. Burgdorf J, Zhang XL, Nicholson KL, Balster RL, Leander JD, Stanton PK, Gross AL, Kroes RA et al (2013) GLYX-13, a NMDA receptor glycine-site functional partial agonist, induces antidepressant-like effects without ketamine-like side effects. Neuropsychopharmacology 38(5):729-742. https://doi.org/10. 1038/npp.2012.246

11. Zorumski CF, Izumi Y (2012) NMDA receptors and metaplasticity: mechanisms and possible roles in neuropsychiatric disorders. Neurosci Biobehav Rev 36(3):989-1000. https://doi.org/10.1016/ j.neubiorev.2011.12.011
12. Duman RS, Li N, Liu R-J, Duric V, Aghajanian G (2012) Signaling pathways underlying the rapid antidepressant actions of ketamine. Neuropharmacology 62(1):35-41. https://doi.org/10.1016/j. neuropharm.2011.08.044

13. Caffino L, Di Chio M, Giannotti G, Venniro M, Mutti A, Padovani L, Cheung D, Fumagalli GF et al (2016) The modulation of BDNF expression and signalling dissects the antidepressant from the reinforcing properties of ketamine: effects of single infusion vs. chronic self-administration in rats. Pharmacol Res 104:22-30. https://doi. org/10.1016/j.phrs.2015.12.014

14. Caffino L, Piva A, Giannotti G, Di Chio M, Mottarlini F, Venniro M, Yew DT, Chiamulera C et al (2017) Ketamine selfadministration reduces the homeostasis of the glutamate synapse in the rat brain. Mol Neurobiol 54(9):7186-7193. https://doi.org/ 10.1007/s12035-016-0231-6

15. Caffino L, Piva A, Mottarlini F, Di Chio M, Giannotti G, Chiamulera C, Fumagalli F (2018) Ketamine self-administration elevates $\alpha$ CaMKII autophosphorylation in mood and rewardrelated brain regions in rats. Mol Neurobiol 55(7):5453-5461. https://doi.org/10.1007/s12035-017-0772-3

16. Zanos P, Moaddel R, Morris PJ, Georgiou P, Fischell J, Elmer GI, Alkondon M, Yuan P et al (2016) NMDAR inhibition-independent antidepressant actions of ketamine metabolites. Nature 533(7604): 481-486. https://doi.org/10.1038/nature17998

17. Vose L, Stanton P (2017) Synaptic plasticity, metaplasticity and depression. Curr Neuropharmacol 15(1):71-86. https://doi.org/10. 2174/1570159x14666160202121111

18. Piva A, Gerace E, Di Chio M, Osanni L, Padovani L, Caffino L, Fumagalli F, Pellegrini-Giampietro DE et al (2018) The metaplastic effects of NMDA receptors blockade on reactivation of instrumental memories in rats. Neurobiol Learn Mem 154:87-96. https://doi. org/10.1016/j.nlm.2018.01.007

19. Piva A, Caffino L, Padovani L, Pintori N, Mottarlini F, Sferrazza G, Paolone G, Fumagalli $F$ et al (2020) The metaplastic effects of ketamine on sucrose renewal and contextual memory reconsolidation in rats. Behav Brain Res 379:112347. https://doi. org/10.1016/j.bbr.2019.112347

20. Paxinos G, Watson C (1998) The rat brain in stereotaxic coordinates. Academic Press

21. Caffino L, Verheij MMM, Roversi K, Targa G, Mottarlini F, Popik P, Nikiforuk A, Golebiowska J et al (2020) Hypersensitivity to amphetamine's psychomotor and reinforcing effects in serotonin transporter knockout rats: glutamate in the nucleus accumbens. $\mathrm{Br}$ J Pharmacol 177(19):4532-4547. https://doi.org/10.1111/bph. 15211

22. Graef JD, Newberry K, Newton A, Pieschl R, Shields E, Luan FN Simmermacher J, Luchetti D et al (2015) Effect of acute NR2B antagonist treatment on long-term potentiation in the rat hippocampus. Brain Res 1609:31-39. https://doi.org/10.1016/j.brainres. 2015.03.019

23. Vezzani A, Serafini R, Stasi MA, Caccia S, Conti I, Tridico RV, Samanin R (1989) Kinetics of MK-801 and its effect on quinolinic acid-induced seizures and neurotoxicity in rats. J Pharmacol Exp Ther 249(1):278-283

24. Rofael HZ, Abdel-Rahman MS (2002) The role of ketamine on plasma cocaine pharmacokinetics in rat. Toxicol Lett 129(1-2): 167-176. https://doi.org/10.1016/s0378-4274(02)00008-5

25. Veilleux-Lemieux D, Castel A, Carrier D, Beaudry F, Vachon P (2013) Pharmacokinetics of ketamine and xylazine in young and old Sprague-Dawley rats. J Am Assoc Lab Anim Sci 52(5):567570

26. Kaiser S, Foltz LA, George CA, Kirkwood SC, Bemis KG, Lin X, Gelbert LM, Nisenbaum LK (2004) Phencyclidine-induced changes in rat cortical gene expression identified by microarray analysis: implications for schizophrenia. Neurobiol Dis 16(1):220-235. https://doi.org/10.1016/j.nbd.2004.01.011 
27. Kristiansen LV, Beneyto M, Haroutunian V, Meador-Woodruff JH (2006) Changes in NMDA receptor subunits and interacting PSD proteins in dorsolateral prefrontal and anterior cingulate cortex indicate abnormal regional expression in schizophrenia. Mol Psychiatry 11(8):737-747, 705. https://doi.org/10.1038/sj.mp. 4001844

28. Feyissa AM, Chandran A, Stockmeier CA, Karolewicz B (2009) Reduced levels of NR2A and NR2B subunits of NMDA receptor and PSD-95 in the prefrontal cortex in major depression. Prog Neuro-Psychopharmacol Biol Psychiatry 33(1):70-75. https://doi. org/10.1016/j.pnpbp.2008.10.005

29. Moghaddam B, Adams B, Verma A, Daly D (1997) Activation of glutamatergic neurotransmission by ketamine: a novel step in the pathway from NMDA receptor blockade to dopaminergic and cognitive disruptions associated with the prefrontal cortex. J Neurosci 17(8):2921-2927. https://doi.org/10.1523/jneurosci.17-08-02921. 1997

30. Zhang JC, Yao W, Dong C, Yang C, Ren Q, Ma M, Han M, Hashimoto K (2015) Comparison of ketamine, 7,8dihydroxyflavone, and ANA-12 antidepressant effects in the social defeat stress model of depression. Psychopharmacology 232(23): 4325-4335. https://doi.org/10.1007/s00213-015-4062-3

31. Yang B, Zhang JC, Han M, Yao W, Yang C, Ren Q, Ma M, Chen QX et al (2016) Comparison of R-ketamine and rapastinel antidepressant effects in the social defeat stress model of depression. Psychopharmacology 233(19-20):3647-3657. https://doi.org/10. 1007/s00213-016-4399-2

32. Kristiansen LV, Meador-Woodruff JH (2005) Abnormal striatal expression of transcripts encoding NMDA interacting PSD proteins in schizophrenia, bipolar disorder and major depression. Schizophr Res 78(1):87-93. https://doi.org/10.1016/j.schres.2005.06.012

33. Kornau HC, Schenker LT, Kennedy MB, Seeburg PH (1995) Domain interaction between NMDA receptor subunits and the postsynaptic density protein PSD-95. Science 269(5231):1737-1740. https://doi.org/10.1126/science.7569905

34. Nicoll RA, Tomita S, Bredt DS (2006) Auxiliary subunits assist AMPA-type glutamate receptors. Science 311(5765):1253-1256. https://doi.org/10.1126/science.1123339

35. Knackstedt LA, LaRowe S, Mardikian P, Malcolm R, Upadhyaya H, Hedden S, Markou A, Kalivas PW (2009) The role of cystineglutamate exchange in nicotine dependence in rats and humans. Biol Psychiatry 65(10):841-845. https://doi.org/10.1016/j. biopsych.2008.10.040

36. Sari Y, Smith KD, Ali PK, Rebec GV (2009) Upregulation of GLT1 attenuates cue-induced reinstatement of cocaine-seeking behavior in rats. J Neurosci 29(29):9239-9243. https://doi.org/10. 1523/jneurosci.1746-09.2009

37. Sari Y, Sakai M, Weedman JM, Rebec GV, Bell RL (2011) Ceftriaxone, a beta-lactam antibiotic, reduces ethanol consumption in alcohol-preferring rats. Alcohol Alcohol 46(3):239-246. https:// doi.org/10.1093/alcalc/agr023

38. Gasull-Camós J, Tarrés-Gatius M, Artigas F, Castañé A (2017) Glial GLT-1 blockade in infralimbic cortex as a new strategy to evoke rapid antidepressant-like effects in rats. Transl Psychiatry 7(2):e1038. https://doi.org/10.1038/tp.2017.7

39. Pham TH, Defaix C, Nguyen TML, Mendez-David I, Tritschler L, David DJ, Gardier AM (2020) Cortical and raphe GABA(A), AMPA receptors and glial GLT-1 glutamate transporter contribute to the sustained antidepressant activity of ketamine. Pharmacol Biochem Behav 192:172913. https://doi.org/10.1016/j.pbb.2020. 172913
40. Jia Y-F, Wininger K, Ho AM-C, Peyton L, Baker M, Choi D-S (2020) Astrocytic glutamate transporter 1 (GLT1) deficiency reduces anxiety- and depression-like behaviors in mice. Front Behav Neurosci 14:57

41. Xi D, Zhang W, Wang HX, Stradtman GG, Gao WJ (2009) Dizocilpine (MK-801) induces distinct changes of N-methyl-Daspartic acid receptor subunits in parvalbumin-containing interneurons in young adult rat prefrontal cortex. Int J Neuropsychopharmacol 12(10):1395-1408. https://doi.org/10. 1017/s146114570900042x

42. Liu X, Li J, Guo C, Wang H, Sun Y, Wang H, Su YA, Li K et al (2018) Olanzapine reverses MK-801-induced cognitive deficits and region-specific alterations of NMDA receptor subunits. Front Behav Neurosci 11:260. https://doi.org/10.3389/fnbeh.2017.00260

43. Xia B, Zhang H, Xue W, Tao W, Chen C, Wu R, Ren L, Tang J et al (2016) Instant and lasting down-regulation of NR1 expression in the hippocampus is associated temporally with antidepressant activity after acute yueju. Cell Mol Neurobiol 36(7):1189-1196. https://doi.org/10.1007/s10571-015-0316-1

44. Calabrese F, Guidotti G, Molteni R, Racagni G, Mancini M, Riva MA (2012) Stress-induced changes of hippocampal NMDA receptors: modulation by duloxetine treatment. PLoS One 7(5):e37916. https://doi.org/10.1371/journal.pone.0037916

45. Li N, Lee B, Liu RJ, Banasr M, Dwyer JM, Iwata M, Li XY, Aghajanian G et al (2010) mTOR-dependent synapse formation underlies the rapid antidepressant effects of NMDA antagonists. Science 329(5994):959-964. https://doi.org/10.1126/science. 1190287

46. Zhang K, Xu T, Yuan Z, Wei Z, Yamaki VN, Huang M, Huganir RL, Cai X (2016) Essential roles of AMPA receptor GluA1 phosphorylation and presynaptic HCN channels in fast-acting antidepressant responses of ketamine. Sci Signal 9(458):ra123. https:// doi.org/10.1126/scisignal.aai7884

47. Zhang K, Yamaki VN, Wei Z, Zheng Y, Cai X (2017) Differential regulation of GluA1 expression by ketamine and memantine. Behav Brain Res 316:152-159. https://doi.org/10.1016/j.bbr.2016. 09.002

48. McCullumsmith RE, Kristiansen LV, Beneyto M, Scarr E, Dean B, Meador-Woodruff JH (2007) Decreased NR1, NR2A, and SAP102 transcript expression in the hippocampus in bipolar disorder. Brain Res 1127(1):108-118. https://doi.org/10.1016/j.brainres.2006.09. 011

49. Ji B, Higa KK, Kim M, Zhou L, Young JW, Geyer MA, Zhou X (2014) Inhibition of protein translation by the DISC1-Boymaw fusion gene from a Scottish family with major psychiatric disorders. Hum Mol Genet 23(21):5683-5705. https://doi.org/10.1093/hmg/ ddu 285

50. Ungless MA, Whistler JL, Malenka RC, Bonci A (2001) Single cocaine exposure in vivo induces long-term potentiation in dopamine neurons. Nature 411(6837):583-587. https://doi.org/10.1038/ 35079077

51. Cahill ME, Bagot RC, Gancarz AM, Walker DM, Sun H, Wang ZJ, Heller EA, Feng J et al (2016) Bidirectional synaptic structural plasticity after chronic cocaine administration occurs through Rap1 small GTPase signaling. Neuron 89(3):566-582. https://doi. org/10.1016/j.neuron.2016.01.031

Publisher's Note Springer Nature remains neutral with regard to jurisdictional claims in published maps and institutional affiliations. 